Для забезпечення стійкої роботи і якісних перехідних процесів необхідно індивідуально підбирати виконавчі механізми і ПІД-параметри з урахуванням умов експлуатації автомобільних дизелів. Робота за низьких частот обертання вимагає малих значень П-складової, а за номінального режиму необхідно збільшувати значення П-складової. Вплив параметрів налаштування мікропроцесорного ПІД-регулятора дизеля на витрату палива відчутно в перехідних процесах. При амплітудах зовнішніх вібрацій $1 . . .3$ мм зменшення І-складової приводить до зменшення витрати палива. За результатами моделювання перехідних процесів економія палива склала 2,25\%.

\title{
EFFECT OF SETTING PARAMETERS OF SPEEDS PID REGULATOR OF DIESEL FOR FUEL CONSUMPTION
}

\section{A.A. Lisoval, A.V. Verbovskiy, V.V. Shtribets}

The purpose of the research is the development of universal recommendations for tuning the microprocessor diesel PIDregulator. The article presents the results: motor testes of the influence of PID parameters on the stability of diesel operation; calculations on the dynamic model of the influence of PID parameters on fuel consumption when adjusting the regulator takes into account the effects of random external vibrations of different amplitudes.

To ensure the stable operation and quality transient processes, it is necessary to select actuators individually and PID parameters taking into account the operating conditions of diesel engines. Operation at low speeds requires a small proportional component, and in the nominal mode it is necessary to increase the value of the proportional component. The effect of the tuning parameters of the microprocessor PID regulator on the fuel consumption is noticeable in transient processes. At amplitudes of external vibrations of $1 \ldots 3 \mathrm{~mm}$, the decrease in the integral component leads to a decrease in fuel consumption. The fuel economy was $2.25 \%$. accordingly to the results of the simulation of transients.

\section{А.В. Грицюк, И.С. Ревелюк, Д.В. Левченко}

\section{МЕТОД ЭКСПЕРИМЕНТАЛЬНО-РАСЧЕТНОГО ОПРЕДЕЛЕНИЯ ЖЕСТКОСТИ КРИВОШИПА КОЛЕНЧАТОГО ВАЛА}

\begin{abstract}
Разработан метод экспериментально-расчетного определения жесткости кривошипа коленчатого вала. Спроектирован и изготовлен специальный стенд для отработки данного метода. Проведена апробация данного метода на примере определения жесткости кривошипа коленчатого вала рядного четырехиилиндрового автомобильного дизеля ДА10. Даны рекомендации по упрощению разработанного метода до инженерного способа экспериментального определения жесткости кривошипа коленчатого вала.
\end{abstract}

\section{Введение}

Предварительное моделирование крутильных колебаний коленчатого вала (КВ) рядного шестицилиндрового малолитражного дизеля [1] показало актуальность проблемы разработки эффективного малогабаритного силиконового демпфера уменьшенной энергоемкости, устанавливаемого на носок КВ. Задача создания шестицилиндровой модификации отечественного автомобильного малолитражного дизеля, стартовав с инвестиционного проекта “Слобожанский дизель”, на сегодняшний день приобрела всеукраинский статус и активизировала продолжение научно-технических работ, направленных на решение обозначенной проблемы. Следующим шагом на этом пути являются расчетные и экспериментально-расчетные исследования по подготовке исходных данных для проектирования силиконового демпфера отечественного автомобильного дизеля ДА15, являющегося следующим поколением рядных шестицилиндровых малолитражных дизелей. Весомой физической величиной в параметрической структуре исходных данных является жесткость кривошипа КВ, определение ко- торой до сегодняшнего дня представляет научную проблему.

Численный анализ сходимости результатов расчетного решения проблемы

Эта проблема пока не имеет общепринятого однозначного решения из-за сложности конструкции этой детали и некоторой неопределенности в моделировании влияния на жесткость вала зазоров в коренных подшипниках. Для определения жесткости КВ применяются расчетные и экспериментальные методы, однако выполнение оценки жесткости КВ с помощью расчетных методов не дает достаточно точных результатов.

Это происходит из-за того, что при расчетах применяются эмпирические формулы. Существует множество различных эмпирических формул для расчета жесткости КВ, как отечественных авторов, так и зарубежных. Наиболее часто применяемыми среди них являются формулы, которые разработаны С.С. Зиманенко, Картером, Кером Вилсоном, С.П. Тимошенко и фирмой Зульцер [2-6]. Однако все эти формулы не учитывают конструктивные особенности КВ, такие как галтели, отверстия для 
подвода масла, форму щек и противовесов и т.д. В свою очередь все эти конструктивные особенности влияют на суммарную жесткость кривошипа. Так, например, экспериментально установлено, что жесткость кривошипа со щеками без скоса на 714\% выше, чем у кривошипа со скосами [4].

Жесткость одного кривошипа КВ складывается из жесткости коренной шейки, жесткости шатунной шейки и жесткостей двух щек. В соответствии с этим эмпирические формулы для определения жесткости состоят из 3-х слагаемых. Во всех формулах при расчетах учитываются лишь диаметр и длина коренной и шатунной шеек, толщина и ширина щек, а также радиус кривошипа и модуль сдвига. Формулы различаются исключительно эмпирическими коэффициентами. Данные коэффициенты подбираются в зависимости от типа двигателя, принадлежностью которого является КВ как объект определения жесткости. Вследствие различия эмпирических коэффициентов, результаты определения жесткости кривошипа конкретного КВ оказываются различными.

Приведенные в таблице 1 расчеты, проведенные по перечисленным выше формулам для кривошипа КВ дизеля серии ДА, показали, что результаты определения жесткости кривошипа КВ различаются почти в 1,35 раза и лежат в диапазоне от 524767,827 до $705708,276 \mathrm{H} \cdot$ м/рад. Такой разброс значений не позволяет остановиться на каком-либо методе расчета и делает актуальным поиск новых методов определения жесткости кривошипа КВ.

\section{Цель и задачи исследования}

Целью данной работы является разработка метода экспериментально-расчетного определения жесткости кривошипа КВ. Для достижения этой цели в работе решается объемная задача от планирования эксперимента до практических рекомендаций по инженерному применению отработанного метода.

\section{Планирование эксперимента}

Необходимость получения аналитических зависимостей, как результата проведенного эксперимента, обосновала предшествующее постановке самого эксперимента его математическое планирование с помощью метода планируемого эксперимента (МПЭ). Применение МПЭ в разнообразных исследованиях дизельной элементной базы и дизелей - в целом факт хорошо известный, однако в данной работе возникла необходимость нестандартного подхода к выбору управляемых факторов и обобщенного оценочного критерия результата эксперимента. В итоге выбраны следующие управляемые факторы: нагружающий момент $M$ и расстояние $L$ от точки приложения данного момента до точки закрепления КВ. Обобщенным оценочным критерием выбрано перемещение $\Delta h$ флажка, устанавливаемого на заданной коренной шейке согласно методике исследований.

Таблица 1. Результаты расчетного определения жесткости кривошипа коленчатого вала дизеля серии ДА

\begin{tabular}{|c|l|c|}
\hline $\begin{array}{c}\text { 일 } \\
\text { ․․․․ }\end{array}$ & $\begin{array}{c}\text { Метод расчетного иссле- } \\
\text { дования }\end{array}$ & $\begin{array}{c}\text { Численное значе- } \\
\text { ние жесткости, } \\
\text { Н·м/рад }\end{array}$ \\
\hline 1 & Формула Зиманенко & 539954,2 \\
\hline 2 & Формула Картера & 705708,3 \\
\hline 3 & Формула Кер-Вильсона & 524767,9 \\
\hline 4 & Формула Тимошенко & 654933,1 \\
\hline 5 & Формула фирмы Зульцер & 581436,8 \\
\hline
\end{tabular}

Выбор рациональной матрицы планирования эксперимента проведен из набора хорошо зарекомендовавших себя вариантов, предложенных в работе [7]. В описываемом случае план эксперимента ограничивался теми экспериментальными точками, которые заложены в ортогональный план второго порядка для двух переменных, соответственно (табл. 2).

Таблица 2. Ортогональный план проведения эксперимента

\begin{tabular}{|c|c|c|c|c|}
\hline \multirow{2}{*}{ 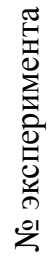 } & \multicolumn{2}{|c|}{$\begin{array}{c}\text { Нормированные } \\
\text { факторы }\end{array}$} & \multicolumn{2}{|c|}{$\begin{array}{c}\text { Действительные } \\
\text { переменные }\end{array}$} \\
\hline & $X_{1}$ & $\mathrm{X}_{2}$ & $M, \mathrm{H} \cdot \mathrm{M}$ & $L, \mathrm{MM}$ \\
\hline 1 & 1 & 1 & 206 & 440 \\
\hline 2 & 1 & -1 & 206 & 226 \\
\hline 3 & -1 & 1 & 69 & 440 \\
\hline 4 & -1 & -1 & 69 & 226 \\
\hline 5 & 0 & 0 & 137,5 & 333 \\
\hline 6 & 1 & 0 & 206 & 333 \\
\hline 7 & -1 & 0 & 69 & 333 \\
\hline 8 & 0 & 1 & 137,5 & 440 \\
\hline 9 & 0 & -1 & 137,5 & 226 \\
\hline
\end{tabular}

\section{Постановка эксперимента}

Для определения жесткости кривошипа КВ экспериментально-расчетным методом был изготовлен специальный стенд, позволяющий:

- надежно закреплять КВ в определенном положении;

- производить двухстороннее нагружение вала заданным нагружающим моментом;

- обеспечить необходимую точность измерения. 
В качестве объекта испытаний выбран уже готовый КВ - прототип разрабатываемому по размерности и конструкции кривошипа, а именно КВ четырехцилиндрового автомобильного дизеля ДА10. Методика определения перемещения коренной шейки испытуемого КВ заключалась в следующем:

1. КВ устанавливался на стенд (рис. 1) на крайние опоры I-й и V-й коренными шейками, и соединялся с траверсой со стороны последней коренной шейки посредством переходной шлицевой втулки. От проворачивания КВ фиксировался с помощью средней опоры, которая благодаря смещению относительно продольной оси вала фиксировала одну из шатунных шеек таким образом, что плоскость кривошипа располагалась горизонтально, как это рекомендовано предыдущими экспериментальными исследованиями [8]. Данное положение КВ минимизирует силу давления на опоры стенда, а, следовательно, и деформацию опор и крепежных болтов (для ослабления влияния этой деформации на точность замеров). КВ последовательно закреплялся на стенде по схемам, представленным на рис. 2-5.
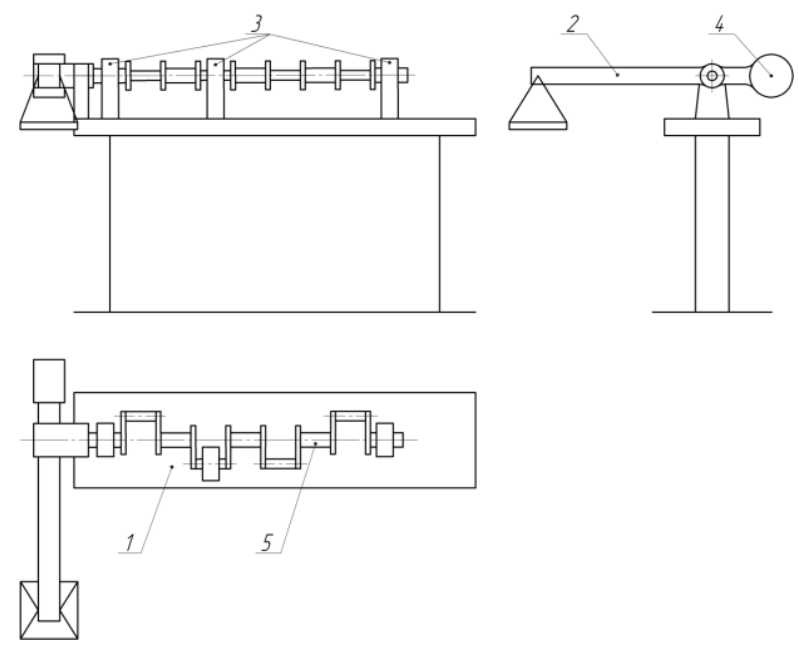

Рис. 1. Схема стенда для определения жесткости коленчатого вала:

1 - стол стенда; 2 - траверса; 3 - опоры; 4 противовес; 5 - коленчатый вал

2. Измерение величины угла закрутки КВ производилось индикатором часового типа с ценой деления 0,01 мм. Индикатор жестко закреплялся на столе стенда, а ножка индикатора касалась флажка, смонтированного на КВ. Расстояние от точки касания флажка ножкой индикатора до оси КВ составляло 90 мм. Флажки были установлены на V-ой (индикатор 1), IV-ой (индикатор 2) и III-ей (индикатор 3) коренных шейках.
3. После закрепления КВ к траверсе прикладывался заданный (табл. 2) нагружающий момент.

4. Производились замеры перемещения флажка $\Delta h$.

5. Действия, описанные в пунктах 3 и 4, повторялись для всех заданных табл. 2 величин нагружающего момента и положений точки закрепления КВ при каждой схеме испытаний.

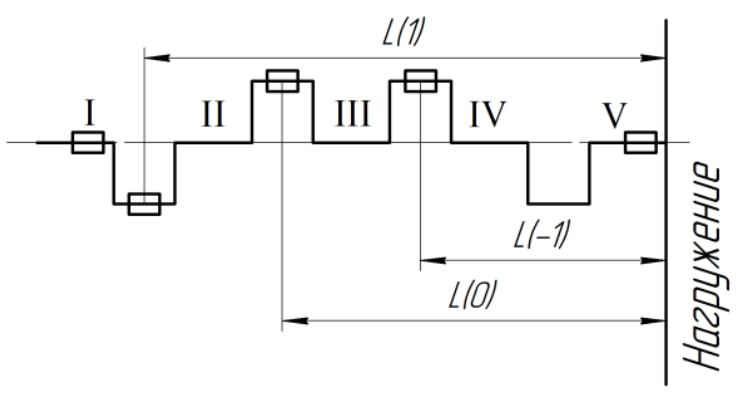

Рис. 2. Схема закрепления коленчатого вала для эксперимента 1

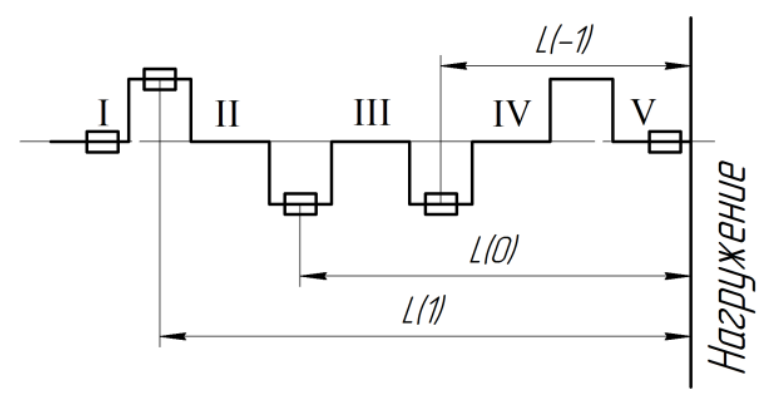

Рис. 3. Схема закрепления коленчатого вала для эксперимента 2

Четыре положения для каждой из точек закрепления КВ выбраны для усреднения полученных результатов вследствие того, что кривошип КВ в процессе испытаний, наряду со скручиванием, подвергается также и изгибу, что вносит существенные искажения в измеряемые величины. Как попытка исключения воздействия изгибающего момента и проводились четыре группы испытаний.

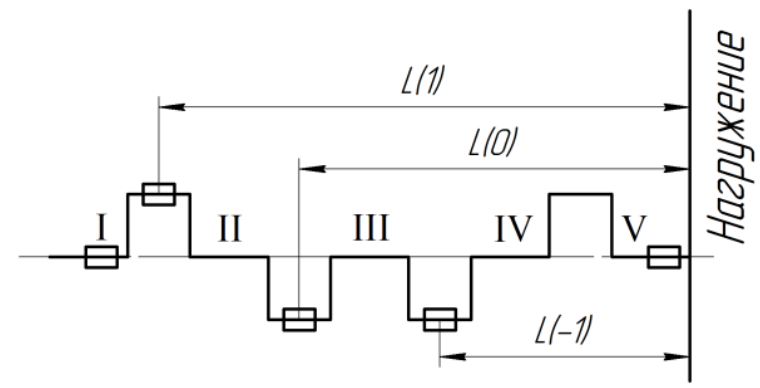

Рис. 4. Схема закрепления коленчатого вала для эксперимента 3 


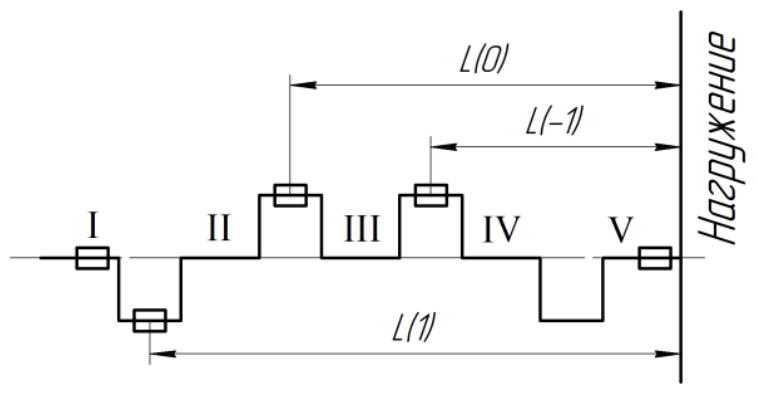

Рис. 5. Схема закрепления коленчатого вала для эксперимента 4

\section{Математическая обработка результатов эксперимента}

Полученные в ходе экспериментальных исследований данные, согласно принятым для постановки эксперимента параметрам варьирования факторов, дали полное описание зависимости численного значения показателя скручивания и изгиба вала от крутящего момента и длины деформируемого участка. Дальнейшая обработка данных свелась к созданию математической модели исследуемой функции и построения графиков, которые позволили сделать выводы о характере зависимости.

Для построения математической зависимости использован широко распространенный и признанный метод аппроксимации - метод наименьших квадратов (МНК). Согласно практике решения подобных задач данную функциональную зависимость с достаточной для инженерных расчетов точностью можно описать степенным полиномом. Если величина скручивания имеет линейную зависимость от крутящего момента и длины вала, то для описания деформации в нашем эксперименте предложено использование полинома второй степени, что повысило точность аппроксимации и позволило сделать выводы о полученных экспериментальных данных.

В данной постановке задачи мы имеем зависимость функции отклика от двух переменных факторов. Полином второй степени, описывающий влияние обоих факторов, принимает следующий вид:

$$
Y=a_{0}+a_{1} x_{1}+a_{2} x_{2}+a_{11} x_{1}^{2}+a_{22} x_{2}^{2}+a_{12} x_{1} x_{2},
$$

где $Y$ - функция отклика; $x_{1}, x_{2}$ - значения переменных факторов; $a_{0}, a_{1}, a_{2}, a_{11}, a_{22}, a_{12}$ - искомые коэффициенты факторов

Для определения коэффициентов методом наименьших квадратов в среде MatLAB была разработана программа ApproximationLSM, которая впервые позволяет обрабатывать экспериментальные данные с количеством независимых факторов до 10. Кроме решения системы уравнений, про- грамма позволяет решить задачу оптимизации построенной функции.

По результатам проведенного расчета, согласно данным экспериментов, были получены коэффициенты полиномов вида:

$$
\Delta h=a_{0}+a_{1} M+a_{2} L+a_{11} M^{2}+a_{22} L^{2}+a_{12} M L .
$$

Для дальнейшего анализа результатов эксперимента программа дала возможность представить графики поверхности функции для комплексной оценки характера зависимости и допустимых пределов варьирования влияющих факторов.

Результаты исследования и практические рекомендации

В результате исследования были получены 12 полиномиальных уравнений (по четыре уравнения на каждый из трех индикаторов, соответствующих четырем положениям закрепления КВ). После этого данные уравнения были сведены в три группы. Каждая группа уравнений описывала перемещение одного индикатора, закрепленного на определенной шейке. В итоге получены три суммарных уравнения, каждое из которых характеризует деформирование определенного участка КВ:

$$
\begin{gathered}
\Delta h_{1}=37,55256+0,17794 M+0,09238 L- \\
-0,00067 M^{2}-0,00044 L^{2}+0,00112 M L, \\
\Delta h_{2}=31,11100-0,06175 M-0,25527 L- \\
-0,00018 M^{2}+0,00044 L^{2}+0,00103 M L, \\
\Delta h_{3}=21,69852-0,16109 M-0,10686 L+ \\
+0,00032 M^{2}+0,00017 L^{2}+0,00028 M L .
\end{gathered}
$$

Так как перемещение каждого индикатора $\Delta h$ определяется величиной нагружающего момента $M$ и зависит от расстояния $L$ между точками приложения обозначенного момента и закрепления КВ, то анализ результатов проведенного исследования целесообразно было провести на основании изучения графических зависимостей $\Delta h=f(M, L)$ при поочередном фиксировании каждой из переменных функции. Двухмерные графики данных зависимостей представлены на рисунках 6-11.

Из графиков зависимости $\Delta h$ индикатора от $L$ видно, что желаемой линеаризации поддаются лишь зависимости для индикатора 2. Аналогичная картина наблюдается и для зависимости $\Delta h$ этого же индикатора от $M$. Проведя линеаризацию, мы выборочно определили $\Delta h_{i}$ при значениях $L$, равных 226, 333 и 440 мм, для нагружающего момента, равного $206 \mathrm{H} \cdot$ м. Значения $\Delta h_{i}$ составили 15,45 и 75 мкм, соответственно. Далее, исходя из условия подобия треугольников, были определены значения 
перемещения $\Delta h_{0 i}$ в точке приложения нагружающего момента. Зная расстояние от оси КВ до точки, в которой ножка индикатора касалась флажка, определили угол скручивания $\Delta \varphi_{i}$ закрепленного участка КВ, и нашли жесткость $C_{i}$ этого участка как отношение приложенного момента $M$ к углу скручивания $\Delta \varphi_{i}$.

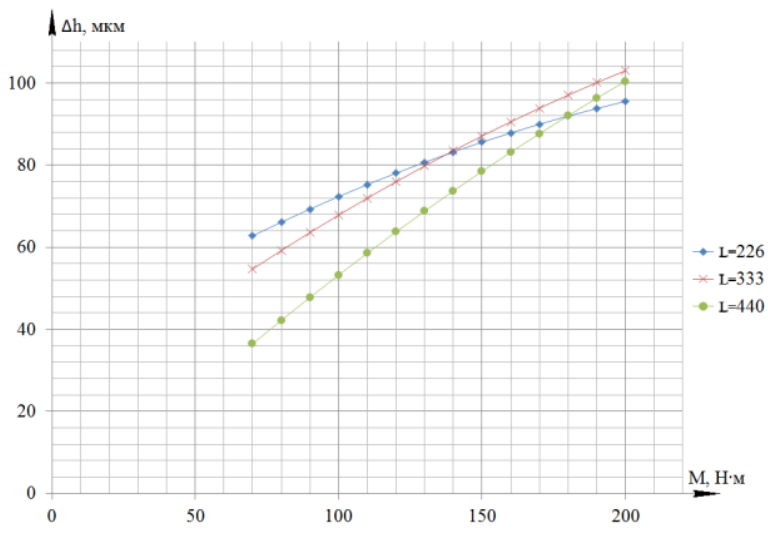

Рис. 6. График зависимости $\Delta$ и индикатора 1 от M при $L=$ const

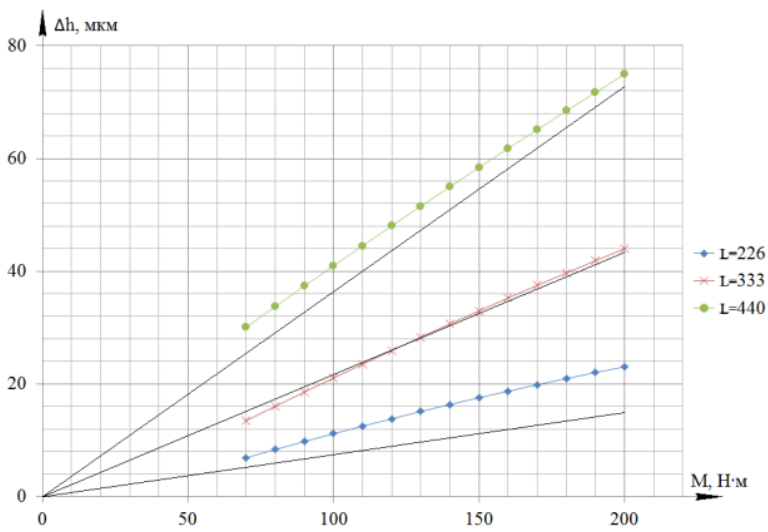

Рис. 7. График зависимости $\Delta$ и индикатора 2 от M npu $L=$ const

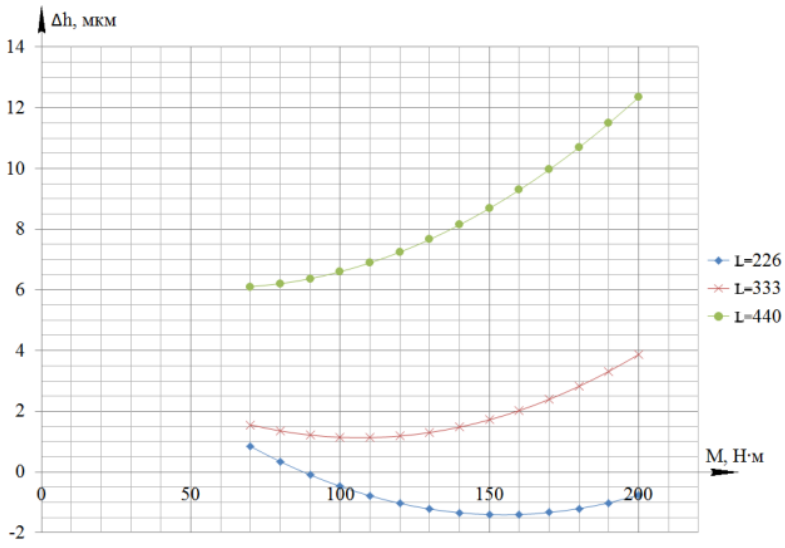

Рис. 8. График зависимости $\Delta$ һ индикатора 3 от M при $L=$ const

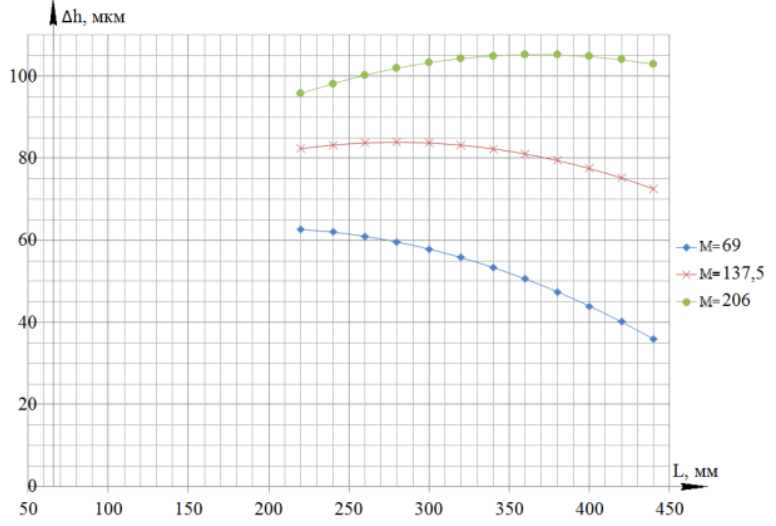

Рис. 9. График зависимости $\Delta$ и индикатора $1 \mathrm{om}$ L при $M=$ const

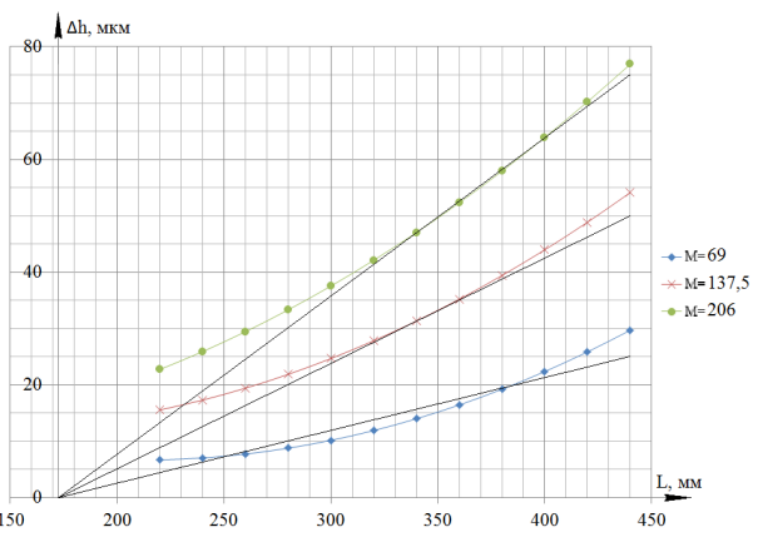

Рис. 10. График зависимости $\Delta h$ индикатора 2 от $L$ nри $M=$ const

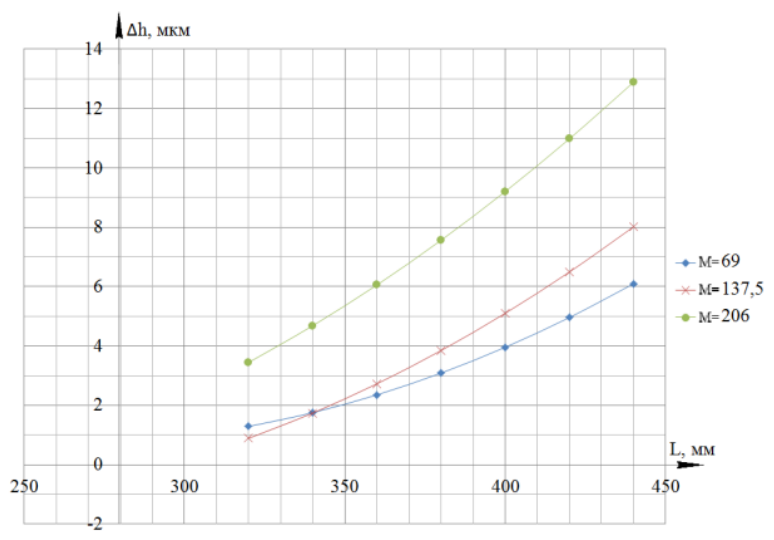

Рис. 11. График зависимости $\Delta h$ индикатора 3 от $L$ при $M=$ const

Жесткость $C_{i}$ закрепленного участка складывается из жесткости фланца КВ, жесткостей n-го количества кривошипов и жесткости половины кривошипа, что видно из схемы закрепления КВ на стенде. Следовательно,

$$
C_{n . k p}=\frac{C_{x} \cdot C_{i}}{C_{x}-C_{i}},
$$


где $C_{x}$ - жесткость фланца КВ; $C_{n . к p}$ - жесткость n-го количества кривошипов.

В итоге была определена жесткость $C_{\kappa p i}$ одного кривошипа

$$
C_{\kappa p i}=n_{\kappa p} \cdot C_{n . \kappa p},
$$

где $n_{к p}$ - количество кривошипов в участке КВ.

Далее найдено усредненное значение жесткости одного кривошипа по формуле:

$$
C_{\kappa p}=\sum_{1}^{3} C_{\kappa p i} / 3=499492,17 \frac{\mathrm{H} \cdot \mathrm{M}}{\text { рад }} .
$$

Как видим, полученное значение жесткости кривошипа КВ отличается от всех значений жесткости, полученных ранее расчетным путем. Вместе с тем оно достаточно близко от этих значений, что позволяет судить о правильности полученных результатов и принять данное значение жесткости для дальнейших расчетов собственных частот системы проектируемого КВ дизеля ДА15.

Вместе с тем, очевидным результатом проведенного (достаточно сложного) исследования является факт получения классических линейных зависимостей $\Delta h=f(M)$ и $\Delta h=f(L)$ только для индикатора 2. Это дает возможность предложить простой инженерный способ (довольно точного) экспериментального определения жесткости кривошипов коленчатых валов рядных вертикальных четырехцилиндровых поршневых двигателей массового применения, позволяя в составе их кривошипно-шатунного механизма, последовательно застопорив поршень первого цилиндра на середине его хода как к ВМТ, так и к НМТ, нагрузить по часовой стрелке и против нее маховик и, измеряя деформацию четвертой коренной шейки, произвести определение искомой жесткости кривошипа.

\section{Выводы}

1. Разработанный метод экспериментальнорасчетного определения жесткости кривошипа КВ позволил с достаточной точностью определить жесткость кривошипа КВ проектируемого отечественного автомобильного дизеля ДА15, что дает возможность вплотную приступить к проектированию силиконового демпфера.

2. Проведение данного исследования позволило предложить простой инженерный способ определения жесткости кривошипов коленчатых валов рядных вертикальных четырехцилиндровых поршневых двигателей.

\section{Список литературы:}

1. Грииюк А.В. Обоснование выбора способа демпфирования крутильных колебаний коленчатого вала высокооборотного дизеля бДТНА на этапе его проектирования / А.В. Гричюк, Ф.И. Абрамчук, В.К. Савич, А.Н. Врублевский, И.С. Ревелюк // Двигатели внутреннего сгорания. 2015. - № 1. - С. 38-43. 2. Ефремов Л.В. Теория и практика исследований крутильных колебаний силовых установок с применением компьютерных технологий / Л.В. Ефремов. - СПб.: Наука, 2007. - 276 с. 3. Prevention of torsional vibration problems in reciprocating machinery: Proceedings of the thirty-eighth turbomachinery symposium / T. Feese, C. Hill. - Texas: Texas A\&M University, 2009. pp. 213-238. 4. Вибрации в технике: Справочник. В 6-ти m. / Ред. совет: В. Н. Челомей (пред.). - М.: Машиностроение, 1980 - . - Т. 3: Колебания машин, конструкиий и их элементов / Под ред. Ф. М. Диментберга и К.С. Колесникова. - 1980. - 544 с. 5. Справочник машиностроителя в шести томах. / Под ред. Н.С. Ачеркана М.: "МАШГИЗ", 1956 - . - Т. 3 / Под ред. С.В. Серенсена. - 1956. - 566 с. 6. Леликов О.П. Валь и опоры с подшипниками качения. Конструирование и расчет: Справочник. / О.П. Леликов. - М.: Машиностроение, 2006. - 640 с. 7. Рафалес-Ламарка Э.Э. Некоторые методы планирования и математического анализа биологических экспериментов / Э.Э. Рафалес-Ламарка, В.Г. Николаев. - Киев: Наукова думка, 1971. - 120 с. 8. Авиационные поршневые двигатели. Кинематика, динамика и расчет на прочность: Пособие для инженеров / [И. А. Биргер, Н. И. Дружинин, В. К. Житомирский и др.J. - М.: Оборонгиз, 1950. - 871 c.

\section{Bibliography (transliterated):}

1. Gritsyuk A.V., Abramchuk F.I., Savich V.K., Vrublevskii A.N., Revelyuk I.S (2015), "Justification of damping method selection of crankshaft torsional vibration of 6DTNA high-rpm diesel at the stage of its design" ["Obosnovanie vybora sposoba dempfirovaniya krutil'nykh kolebanii kolenchatogo vala vysokooborotnogo dizelya 6DTNA na etape ego proektirovaniya"], Internal combustion engines [Dvigateli vnutrennego sgoraniya], no. 1, pp. 38-43. 2. Efremov L.V. (2007), Theory and practice of research of powerplants torsional vibrations via use of computer technologies [Teoriya $i$ praktika issledovanii krutil'nykh kolebanii silovykh ustanovok s primeneniem komp'yuternykh tekhnologii], Nauka, St. Petersburg, 276 p. 3. Feese, T., Hill, C. (2009), Prevention of torsional vibration problems in reciprocating machinery. In: Proceedings of the thirtyeighth turbomachinery symposium, college station TX, Turbomachinery Laboratory, Texas A\&M University, pp. 213-238. 4. Dimentberg F.M., Kolesnikov K.S. (1980), "Vibrations of machines, constructions and their elements" Vol. 3 ["Kolebaniya mashin, konstruktsii $i$ ikh elementov" t. 3], Vibration in engineering: the quick reference. In 6 vol. [Vibratsii v tekhnike: Spravochnik. V 6-ti t.], Mashinostroenie, Moscow, 544 p. 5. Serensen S.V. (1956), "Vol. 3", Handbook of machine builder in six volumes. [T. 3, Spravochnik mashinostroitelya $v$ shesti tomakh], "MAShGIZ", Moscow, 566 p. 6. Lelikov O.P. (2006), Shafts and supports with rolling bearings. Design and calculation: Handbook. [Valy $i$ opory s podshipnikami kacheniya. Konstruirovanie $i$ raschet: Spravochnik], Mashinostroenie, Moscow, 640 p. 7. Rafales-Lamarka E.E., Nikolaev V.G. (1971), Some design methods and mathematical analysis of biological experiments [Nekotorye metody planirovaniya $i$ matematicheskogo analiza biologicheskikh eksperimentov], Naukova dumka, Kiev, 120 p. 8. Birger I. A., Druzhinin N. I., Zhitomirskii V. K. (1950), Aviation reciprocating engines. Kinematics, dynamics and strength calculation: Manual for engineers [Aviatsionnye porshnevye dvigateli. Kinematika, dinamika $i$ raschet na prochnost': Posobie dlya inzhenerov], Oboron-giz, Moscow, 871 p. 
Грицюк Александр Васильевич - докт. техн. наук, с.н.с., главный конструктор "Научно-производственного предприятия Дизель Групп”, Харьков, Украина, e-mail: nppdg@ukr.net.

Ревелюк Иван Сергеевич - аспирант кафедры ДВС Харьковского национального автомобильно-дорожного университета, Харьков, Украина, e-mail: norad88@mail.ru

Левченко Денис Вадимович - магистр кафедры ДВС Харьковского национального автомобильно-дорожного университета, Харьков, Украина, e-mail: denislev4enko@gmail.com

\title{
МЕТОД ЕКСПЕРИМЕНТАЛЬНО-РОЗРАХУНКОВОГО ВИЗНАЧЕННЯ ЖОРСТКОСТІ КРИВОШИПУ КОЛІНЧАСТОГО ВАЛУ
}

О.В. Грицюк, І.С. Ревелюк, Д.В. Левченко

Розроблено метод експериментально-розрахункового визначення жорсткості кривошипа колінчастого вала. Спроектований і виготовлений спеціальний стенд для відпрацювання даного методу. Проведено апробацію цього методу на прикладі визначення жорсткості кривошипа колінчастого вала рядного чотирициліндрового автомобільного дизеля ДА10. Надано рекомендації щодо спрощення розробленого методу до інженерного способу експериментального визначення жорсткості кривошипа колінчастого вала.

\section{METHOD OF EXPERIMENTAL AND CALCULATED DETERMINATION OF THROW STIFFNESS OF CRANKSHAFT}

\section{A.V. Gritsuk, I.S. Revelyuk, D.V. Levchenko}

The method of experimental and calculation determination of throw stiffness of crankshaft has been developed. A special stand for testing this method has been designed and manufactured. Approbation of this method on example of determining throw stiffness of crankshaft of DA10 inline four-cylinder diesel engine has been led. Recommendations concerned simplification the developed method to an engineering method of experimental determination of throw stiffness of crankshaft have been given.

\section{В.Г. Заренбин, Т.Н. Колесникова}

\section{К РАСЧЕТУ ТЕЧЕНИЯ ГАЗОВ ЧЕРЕЗ КОЛЬЦЕВЫЕ УПЛОТНЕНИЯ ДВС С УЧЕТОМ ДИНАМИКИ ПОРШНЕВЫХ КОЛЕЦ}

\begin{abstract}
Предложена математическая модель течения газов через кольиевые уплотнения иилиндро-поршневой группы, которая учитывает дросселирующее влияние верхнего пояса поршня и изменения проходных сечений и объемов кольцевого лабиринта, вызванных перемещением поршневых колеи в канавках поршня. Представлены расчетные и экспериментальные данные по перемещению поршневых колеи в канавках поршня. Отмечается существенное влияние поведения второго компрессионного кольца на динамическую устойчивость кольцевого уплотнения. Сопоставление экспериментальных данных с результатами расчетов показывает их удовлетворительную сходимость.
\end{abstract}

Введение

Постановка проблемы. Любое стремление повысить надежность и долговечность современных ДВС сталкивается с проблемой совершенствования поршневых колец (ПК), поскольку всякое даже незначительное нарушение их работы может вызвать такие нежелательные дефекты как усиленный износ, перерасход горючесмазочных материалов, интенсивное нагарообразование и т.д., приводящие в отдельных случаях к поломке двигателя [1].

Анализ выполненных работ показывает, что для успешного решения этой проблемы необходимо учитывать сложный комплекс явлений, связанных с условиями течения газов через кольцевой лабиринт поршня, характером смазки и трения в сопряженных поверхностях, особенностями движения и деформаций деталей цилиндропоршневой группы от действующих сил.
До сих пор наши знания об этих явлениях недостаточны и не позволяют получить приемлемые для практики достоверные количественные зависимости, поэтому требуется проведение дополнительных углубленных как теоретических, так и экспериментальных исследований.

Предложенные математические модели $[2,3,4,5]$ оставляют неясным вопрос о расчете течения газов с учетом изменения геометрических соотношений внутри кольцевого лабиринта во время работы двигателя, вызванных, в частности, перемещением ПК в канавках поршня. Хотя этот фактор, как свидетельствуют экспериментальные исследования перемещения ПК на работающих двигателях $[2,3,4,5]$, нельзя не принимать во внимание, так как он непосредственно влияет на величины как проходных сечений в кольцевом уплотнении, так и объемов канавочных пространств.

В работе [3] предложена интегральная модель функционирования ПК с учетом динамического 